\title{
Effects of a Training Module on Omani Teachers' Awareness of Gifted Students with Learning Disabilities
}
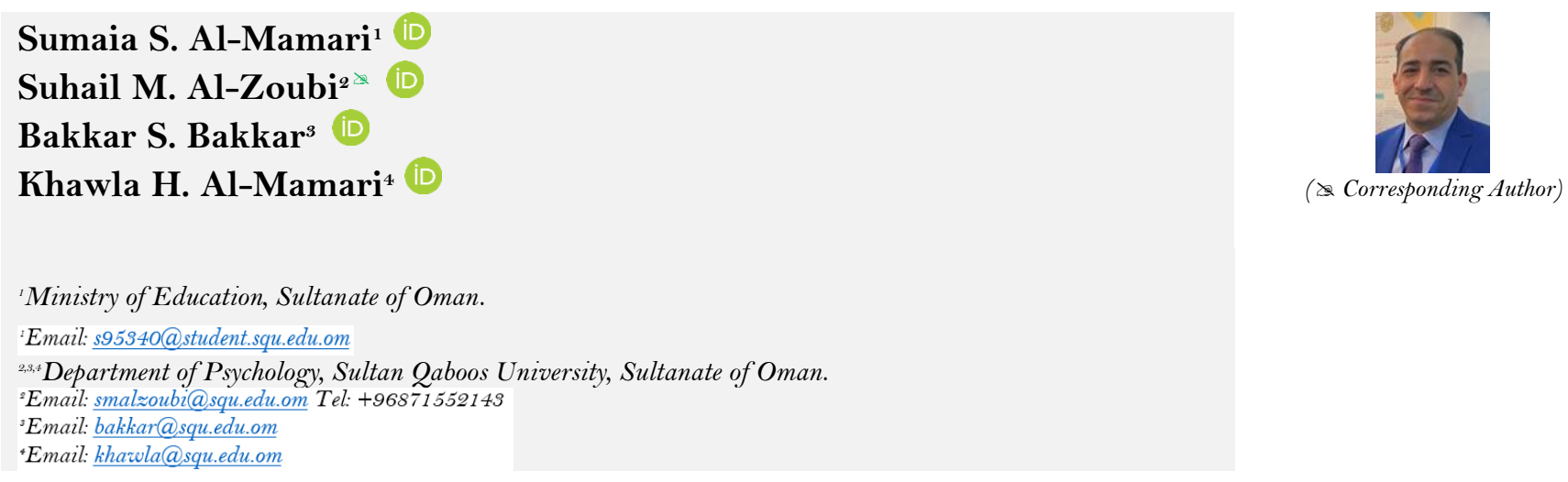

Abstract

The COVID-19 pandemic has led to the use of online and e-learning in Omani general and higher education institutions. Consequently, the pandemic imposed contemporary technological challenges when considering training programs for Omani teachers. This research seeks to record proactive steps, at the Omani and Arab levels, to examine the effectiveness of online, in-service teacher training programs. In addition, this research seeks to explore the effects of online training modules on teachers' knowledge of Gifted Students with Learning Disabilities (GSLD). In other words, the research aims to examine the effects of a training module on Omani teachers' awareness of GSLD. According to a convenience sampling method, a total of 60 Omani teachers participated in the research. Participants were teachers of students with Learning Disabilities (LD) at the resource room program in the Muscat Governate, in the Sultanate of Oman. They were distributed equally into two groups: control $(n=30)$, and experimental $(n=30)$. Following the development of a SelfAwareness Scale (SAS) and the training program module, the SAS was administered to both groups as a pre-test and a post-test. The teachers in the experimental group received a two-week online training module to improve their awareness of GSLD. Results indicated that there were significant differences in the post-test of the SAS in favor of teachers in the experimental group.

Keywords: GSLD, knowledge awareness, module, Omani teachers, Personal awareness, Skill awareness, Training program.

Citation | Sumaia S. Al-Mamari; Suhail M. Al-Zoubi; Bakkar S. Bakkar; Khawla H. Al-Mamari (2020). Effects of a Training Module on Omani Teachers' Awareness of Gifted Students with Learning Disabilities. Journal of Education and e-Learning Research, 7(3): 300305.

History:

Received: 10 June 2020

Revised: 14. July 2090

Accepted: 17 August 2020

Accepted: 17 August 2020
Published: 1 September 2020

Licensed: This work is licensed under a Creative Commons

Attribution 3.0 License (oc))

Publisher: Asian Online Journal Publishing Group
Acknowledgement: The researchers extend their sincere thanks and appreciation to teachers of students with $\mathrm{LD}$ who were recruited for this appreciation to teachers of students with LD who were recruited for this
research and the reviewers who made the utmost effort to revise the SAS and research and the reviewers who
the training program modules.

Funding: This study received no specific financial support.

Competing Interests: The authors declare that they have no conflict of interests.

Transparency: The authors confirm that the manuscript is an honest, accurate, and transparent account of the study as it was reported; that no vital features of the study have been omitted; and that any discrepancies from the study as planned have been explained.

Ethical: This study follows all ethical practices during writing.

\section{Contents}

1. Introduction

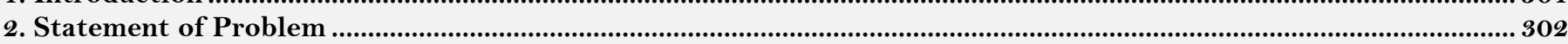

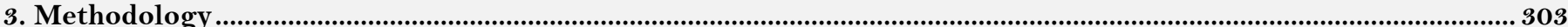

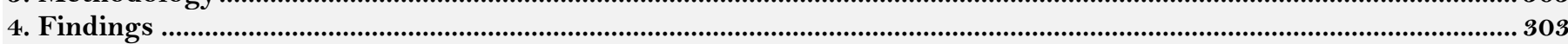

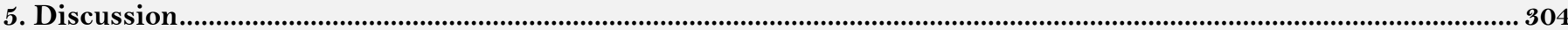

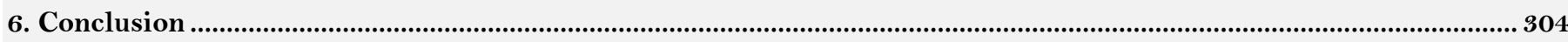

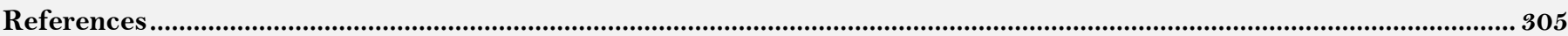




\section{Contribution of this paper to the literature}

This research contributes to determining the role of in-service training programs in improving Omani teachers' awareness of GSLD. Accordingly, conducting this online training module is a qualitative contribution to literature. Therefore, the COVID-19 pandemic has contributed to the rethinking of Omani teacher training programs to convert from conventional methods to online ones.

\section{Introduction}

There is a debate between scholars and theorists whose research studies have focused on the term GSLD; that is, they were used to calling them dual or twice-exceptional children. Moreover, this term does not only encapsulate GSLD, but also includes other categories, such as Gifted with Autism Spectrum Disorder, Gifted with Emotional and Behavioral Disorders, Gifted with Sensory Impairments, Gifted with Physical Disabilities (Al-Hroub, 2010a; Reis, Baum, \& Burke, 2014), and Gifted with ADHD (Al-Hroub \& Krayem, 2018). What is more, Al-Dababneh, AlMasa'deh, and Oliemat (2014) also referred to another category called Creative Students with Disabilities. While this category received a small degree of interest in research and literature, it is necessary to conduct research to identify its characteristics.

Dual/twice-exceptional children are those students who can be identified as having one or more exceptional abilities in academic achievement, intelligence, creativity, leadership, or visual arts. However, they have difficulties in these aspects (Al-Hroub, 2010b). That is, twice-exceptional children have distinct abilities in one or more scientific, social, or human aspect, but, simultaneously, have one or more disability in either physical or cognitive development (Kurup \& Dixit, 2016).

The term twice-exceptional refers to any student with a disability (e.g., with a LD or cerebral palsy) who is also gifted. (Hallahan, Kauffman, \& Pullen, 2014). Cline and Hegeman (2001) asserted that there are specific barriers to the identification of giftedness in populations of students with disabilities. These barriers focus on the assessment of the disability without attention to possible talents, disability-specific concerns overshadowing possible gifts or talents, or stereotypical expectations associated with physical or global intelligence expectations (Cline \& Hegeman, 2001). To address the issue of the under-identification of giftedness in individuals with disabilities, schools need to become advocates for the identification of gifts in all populations of students. Hallahan et al. (2014) recommended that parents, school personnel, and the community should take active roles in supporting the unique needs of students with gifts.

Children who are twice-exceptional are sometimes referred to as 'paradoxical learners.' Gifted students who are learning disabled exhibit characteristics such as easily distracted, inattentive, and inefficient at learning while, at the same time, presenting patterns typical of students who are gifted (Gargiulo, 2012). Students are considered twiceexceptional because they, statistically, fall into the exceptional range for their cognitive, academic, or creative abilities and potential, and also fall in the lower end of being exceptional in the learning deficit area (Beckmann \& Minnaert, 2018).

A common difficulty encountered by professionals working with gifted and twice-exceptional students is that the definition of the word 'gifted' varies widely. Researchers and practitioners often use cognitive ability measures, such as the Wechsler Intelligence Scale for Children (WISC), in which a student's IQ must fall at or above a cut score (often 120 or higher) to ascertain giftedness. Within the use of this parameter, there is a wide range of disagreement regarding how to best utilize these scores, as some researchers argue for the use of higher cutoffs, and others prefer using Full Scale IQs over-index scores to avoid over-diagnosis of LD in gifted students when other factors, such as low motivation, may be the actual cause of the score discrepancy (Assouline, Foley, \& Whiteman, 2010; Lovett \& Sparks, 2011).

In a review of the literature on diagnosing twice-exceptional students with LD, Lovett and Sparks (2011) concluded that the lack of consensus surrounding how to accurately diagnose children who often were achieving within the average range brought the category of GSLD into question. Some researchers even question whether the identification of twice-exceptionality provides unfair advantages to students of affluent parents who have the means to access resources within both systems (Lovett, 2013).

Accordingly, it seems that discussions between scholars and theorists in Special Education were constructive and fruitful, which led to the acceptance of the synchronization and association between giftedness and disability. This association may negatively affect self-concept, self-esteem, and academic achievement in the gifted category which points to special programs different from those offered to students with or without Special Education or categories with other disabilities (Al-Hroub, 2007; Al-Hroub, 2010a).

Twice-exceptional children often receive a great deal of care for their disability, but the identification of their gifts and talents is omitted or ignored by family, school, or community. Consequently, this category should receive consideration and support to identify and develop their special abilities in different stages of childhood.

The association of gift and disability greatly contributed to the classification of GSLD within twice-exceptional children; that is, GSLD academically excel and have distinguished abilities, but they concurrently have disabilities in some learning aspects (Beckmann \& Minnaert, 2018). This association also contributed to the diminishing knowledge and awareness of teachers in identifying GSLD (Al-Hroub \& Whitebread, 2008). Moreover, it may result in negative emotional and psychological responses, such as low motivation in GSLD. Also, teaching strategies used with them may become less effective as they get older in upcoming school stages. To alleviate the intensity of these negative responses in GSLD, their teachers should receive training courses and workshops to provide effective teaching strategies to contribute towards helping these students develop their abilities.

While GSLD have the ability to highly achieve, they, nonetheless, have LD in some aspects of their academic achievements. In this context, Buică-Belciu and Popovici (2014) maintained that GSLD are heterogeneous students described as twice-exceptional children who demonstrate confused behaviors, high abilities, and exceptional understanding of abstract ideas and concepts, but, nevertheless, who have dyslexia, dyscalculia, or a disability in phonological awareness. These characteristics were demonstrated by Maddocks (2018), who asserted that these children have distinguished intellectual abilities that are accompanied by specific LD. Al-Hroub (2014) mentioned 
that there is still ambiguity in this category because of dissensus and disagreement on a unified definition of the term GSLD. To eliminate this lack of certainty, Al-Hroub (2010b) suggested a multidimensional model to identify this category and its merit to receive Special Education services. This model includes diagnostic criteria, specially Discrepancy Criterion, to distinguish between intelligence and academic achievement by administering intelligence tests, standardized achievement tests, and creative tests. Without this, GSLD may be erroneously diagnosed with ADHD, Conduct Disorder, and Autism Spectrum Disorder.

Silverman (2005) explains that the erroneous diagnosis of GSLD may be due to a moderate academic achievement that undermines their gifts. Agarwal and Singh (2011) contended that 33\% of students with LD have superior intellectual abilities, which help them to excel. To identify the high intellectual abilities of these students, Assouline et al. (2010) recommended the necessity of conducting comprehensive assessments of cognitive, academic, psychological, and social characteristics of GSLD; that is, this assessment will contribute to identifying twiceexceptional children.

It seems, as mentioned previously, that the gap in studying this category in literature is a result of the challenges related to the identification of GSLD, and the extent to which teachers give these children educational attention, care, and research. Furthermore, the problem is not the process of identification by relevant professionals and practitioners, but in using sound and reliable criteria for the identification itself. Some practitioners and teachers believe it is necessary to focus on learning disabilities, rather than the distinguished abilities of GSLD because otherwise it is time-consuming and takes great effort on their part. Since the identification of the gifted is not unanimous in professionals in Special Education settings, taking care of GSLD is not a priority for them; that is, their principal work is to help these individuals deal more with their cognitive disabilities than their gifts. Accordingly, different methods are used to make a comprehensive assessment of twice-exceptional children. One of these is the multidimensional approach, which includes psychometric assessments, behavioral checklists, portfolio reviews, and interviews (Reis et al., 2014).

A combination of formal and informal measures is useful in determining if a student is twice-exceptional or simply a gifted student who is underachieving. When twice-exceptional students are not achieving expectations, they may be misidentified as gifted underachievers. They may present some of the same behaviors and outcomes as twiceexceptional students, such as an inability to be organized or unexplained differences between test scores and classroom performance (Josephson, Wolfgang, \& Mehrenberg, 2018).

The prevalence of GSLD, regionally, and internationally, contributes to the need to reconsider the preparation of pre-service and in-service programs for Special Education teachers, and the vision of resource rooms. Al-Zoubi and Al-Zoubi (2020) mentioned that the prevalence of GSLD of the total individuals of students with LD who joined the Jordanian Resource Room Program is 10\%, while Bakhiet and Essa (2012) asserted that the prevalence of GSLD of the total individuals with LD who joined the Saudi Resource Room Program is 3.3\%. Al Hajeri (2015) indicated that $36 \%$ of the total LD are gifted. The prevalence of students with LDs in gifted education programs is $2-10 \%$ (Morrison \& Rizza, 2007).

In-service training programs contribute to improving teachers' job satisfaction which, in turn, positively affects students' performance (Pecháčková, Drahokoupilová, \& Krámová, 2015). These programs help to shape teacher behavior by focusing on cognitive abilities and the ability to overcome emotional problems. Accordingly, teachers of students with LD need in-service training programs that play an important role in ameliorating their knowledge and awareness of GSLD. Training modules (flexible and professional curriculum modules), which are directed to curriculum systems, play an important role in developing talents, and cultivating students' innovation and practical abilities. Therefore, it is recommended that to identify and cultivate high-quality engineering and technical talents; these programs should be implemented and promoted (Wang, Cheng, \& Wang, 2017). Because of teachers' minimal attention toward giftedness and the distinguished abilities of students with LD, there must be awareness programs with goals to concentrate on all characteristics of children with LD, whether those relate to disabilities or distinguished abilities. Training modules or programs pertaining to the identification and education of students with LD should be continuous and periodical so that these programs keep up with the latest strategies of diagnosing and teaching students with LD.

\section{Statement of Problem}

It seems that teachers have problems in identifying GSLD, and meeting their teaching needs in classrooms (Lovett \& Sparks, 2011; Pepanyan, Fisher, \& Wallican-Green, 2018). Locally, there are no programs related to the education of gifted and talented students in the Sultanate of Oman, particularly those who have LDs. What complicates the position of Special Education in Oman is the unavailability of academic programs intended to prepare highly qualified professionals to deal with the gifted in Omani universities. This leads teachers of students with LD to bear the burden of identifying GSLD and to teach them with their peers in an Omani Resource Room Program. By reviewing the efforts made, the Omani Ministry of Education is conducting in-service training programs for teachers. It sounds as if these programs deal with general topics related to teaching strategies, assessment methods, and curricular activities, but they do not have training topics concerning Special Education, particularly the education of the gifted. This deficit may negatively affect the performance of teachers of students with LD, their self-efficacy, and awareness of their teaching role and their educational competencies.

The field of Special Education in the Sultanate of Oman urgently needs specialized workshops (Al-Mamari, 2017) and training programs, intended for teachers of students with LD. These will increase their self-awareness, knowledge, and performance competencies to identify GSLD and to offer remedial instruction programs that are suitable to them. Wormald (2008) indicated that schools and programs of LD often fail to identify GSLD. These findings were an impetus to conduct the current research, particularly as a number of Arabic research initiatives revealed the effectiveness of in-service training programs in increasing awareness of teachers of students with LDs, and teachers of the gifted (Al-Zoghby, 2014). The findings of a pilot study, conducted by the authors, on teachers of students with LD joining a master's degree program of LD indicated they need to identify GSLD, their characteristics, and teaching strategies that are suitable to them. Consequently, the current research is aimed at examining the effects of a training module on Omani teachers' awareness of GSLD. 


\section{Methodology}

\subsection{Study design}

Nonequivalent Control Group Design as a Quasi-Experimental Design used in current research included two groups: an experimental group, whose teachers received the training module, and a control group, who did not receive the module. The SAS was administered to both groups as a pre-test and a post-test.

\subsection{Subjects}

A convenience sample used in this research represented the subjects who voluntarily agreed to participate in it. This method of sampling was utilized because of the exceptional conditions of COVID-19; that is, the work of educational institutions was governmentally suspended. The subjects are female teachers of $\operatorname{LD}(n=60)$ in the Muscat Governorate, and they represent $43 \%$ of the total population of 141 female teachers of students with LD. The subjects $(\mathrm{n}=60)$ were randomly assigned to two groups: experimental and control.

\subsection{Measurement}

\subsubsection{Self-Awareness Scale (SAS)}

The SAS aims to explore Omani teachers' awareness of GSLD. The first version of the SAS consisted of 40 items divided into three domains: knowledge awareness, skill awareness, and personal awareness. To verify the psychometric characteristics of the SAS, face validity was assessed by a panel of faculty members at the Department of Psychology at Sultan Qaboos University. Accordingly, the final version consisted of 40 items. Each item on the SAS required a response based on a four-point Likert scale, from always (4) to rarely (1). The maximum score of the scale is 160 , and the minimum score is 40 . To assess reliability, the SAS was administered to a pilot study of 48 teachers of students with LD. Reliability coefficients of the domains by Cronbach's Alpha were found: knowledge awareness 0.94, skill awareness 0.96, and personal awareness 0.95. In addition, the following criterion was used to assess the level of teachers' awareness of the GSLD: low (1:00 to 1.99), moderate (2.00 to 2.99), and high (3.00 to 4:00).

\subsection{The Training Module}

This program was constructed based on relevant literature reviews. It consisted of 13 training sessions on the following topics: conceptual and theoretical foundations of twice-exceptional children and GSLD, educational placements and settings of GSLD, enrichment, and acceleration of GSLD, emotional and social problems of GSLD, methods of identification of GSLD, applying multiple intelligence theory to GSLD, counseling GSLD and families, behavioral methods in teaching GSLD, and cognitive and metacognitive methods of teaching GSLD. The program also included activities, exercises, and homework assignments.

Due to the exceptional circumstances of the COVID-19 pandemic and the suspension of school and college study, the training module was conducted on female teachers of the experimental group online via Zoom and Google Meet and using the application WhatsApp to simplify and enhance contact with the group's participants. Accordingly, AlZoubi (2019) recommended that teachers of students with LD should seek to acquire the knowledge and skills of the 21 st century by integrating information and communication technology in educational environments.

\section{Findings}

To verify the equivalence of experimental and control groups in the pre-test of the SAS, a t-test was used. Table 1 illustrates the results of the t-test.

\begin{tabular}{|c|c|c|c|c|c|c|}
\hline Domains & Group & df & $\mathbf{M}$ & SD & $\mathrm{t}$ & $\mathbf{P}$ \\
\hline \multirow[t]{2}{*}{$\mathrm{KA}$} & Experimental & \multirow[t]{2}{*}{59} & 2.49 & 0.60 & \multirow[t]{2}{*}{0.471} & \multirow[t]{2}{*}{0.639} \\
\hline & Control & & 2.41 & 0.71 & & \\
\hline \multirow[t]{2}{*}{$\mathrm{SA}$} & Experimental & \multirow[t]{2}{*}{59} & 2.36 & 0.71 & \multirow[t]{2}{*}{0.181} & \multirow[t]{2}{*}{0.857} \\
\hline & Control & & 2.39 & 0.70 & & \\
\hline \multirow[t]{2}{*}{$\mathrm{PA}$} & Experimental & \multirow[t]{2}{*}{59} & 2.87 & 0.73 & \multirow[t]{2}{*}{0.038} & \multirow[t]{2}{*}{0.970} \\
\hline & Control & & 2.88 & 0.67 & & \\
\hline \multirow[t]{2}{*}{ Total } & Experimental & \multirow[t]{2}{*}{59} & 2.57 & 0.57 & \multirow{2}{*}{0.087} & \multirow{2}{*}{0.931} \\
\hline & Control & & 2.56 & 0.63 & & \\
\hline
\end{tabular}

Note: KA: Knowledge Awareness, SA: Skill Awareness, PA: Personal Awareness, M: Mean, SD: Standard Deviation, t: t-value, P: Probability.

Table-2. Results of the t-test in the SAS post-test

\begin{tabular}{|c|c|c|c|c|c|c|c|c|}
\hline Domains & Group & df & $\mathbf{M}$ & SD & $t$ & $\mathbf{P}$ & $\eta^{2}$ & Level \\
\hline \multirow[t]{2}{*}{$\mathrm{KA}$} & Experimental & \multirow[t]{2}{*}{59} & 3.48 & 0.54 & \multirow[t]{2}{*}{6.913} & \multirow[t]{2}{*}{0.01} & \multirow[t]{2}{*}{0.66} & \multirow[t]{2}{*}{ High } \\
\hline & Control & & 2.50 & 0.57 & & & & \\
\hline \multirow[t]{2}{*}{$\mathrm{SA}$} & Experimental & \multirow[t]{2}{*}{59} & 3.35 & 0.57 & \multirow[t]{2}{*}{5.775} & \multirow[t]{2}{*}{0.01} & \multirow[t]{2}{*}{0.59} & \multirow[t]{2}{*}{ High } \\
\hline & Control & & 2.50 & 0.57 & & & & \\
\hline \multirow[t]{2}{*}{ PA } & Experimental & \multirow[t]{2}{*}{59} & 3.53 & 0.45 & \multirow[t]{2}{*}{4.921} & \multirow[t]{2}{*}{0.01} & \multirow[t]{2}{*}{0.53} & \multirow[t]{2}{*}{ High } \\
\hline & Control & & 2.82 & 0.65 & & & & \\
\hline \multirow[t]{2}{*}{ Total } & Experimental & \multirow[t]{2}{*}{59} & 3.45 & 0.50 & \multirow{2}{*}{6.272} & \multirow{2}{*}{0.01} & \multirow[t]{2}{*}{0.62} & \multirow[t]{2}{*}{ High } \\
\hline & Control & & 2.61 & 0.54 & & & & \\
\hline
\end{tabular}

Note: KA: Knowledge Awareness, SA: Skill Awareness, PA: Personal Awareness, M: Mean, SD: Standard Deviation, t: t-value, P: Probability, ฤ2: Eta squared (effect size). 
Table 1 shows that there were no significant differences, $\mathrm{t}=(0.471,0.181,0.038,0.087), \mathrm{P}=(0.639,0.857,0.970$, $0.931)$ respectively in all domains and the total of the SAS. This means that both groups are equivalent to the pretest of the SAS.

Results related to the main research hypothesis: there were no significant differences between both groups on the post-test of the SAS due to the training module. To test this hypothesis, the t-test was utilized according to Table 2. Table 2 showed that there were significant differences in teachers' awareness, $\mathrm{t}=(6.913,5.775,4.921,6.272)$, respectively, $\mathrm{P}=(\mathrm{O} .01)$ in all dimensions and the total. These results indicated that there were significant differences in the post-test of the SAS in favor of teachers in the experimental group. The results of the t-test reject the null hypothesis and accept the alternative one, which confirms the existence of significant differences between both groups. Eta squared $\left(\eta^{2}\right)$ indicates that the effect of the training module was high, $\eta^{2}=0.62, \mathrm{P}=(0.01)$, which means that this module improved knowledge awareness, skill awareness, and personal awareness among teachers in the category of GSLD.

\section{Discussion}

The findings of this research revealed that there exists a significant effect of the training module on improving teachers' awareness of students with LDs. The mean of the total pre-test of the SAS was 2.57 in teachers of the experimental group, while the total post-test of the SAS was 3.45. Effect size $\left(\eta^{2}\right)$ of the training module was 0.62, which means that this module improved teachers' awareness of GSLD. These findings can be explained by acknowledging the teacher as one of the core elements of the educational institutions. Therefore, these institutions should strive to get teachers involved in in-service training programs so that they can keep up with research and scientific developments in the field of GSLD. Al-Zoubi and Nefaie (2019) indicated that most of the challenges that face the LD program are the lack of pre-service professional preparation in teachers of students with LD and the reduction of pre-service training courses and workshops. Al-Zoubi and Rahman (2016) recommended that teachers of students with LD should be involved in pre-service training courses and workshops to improve their knowledge and skills which, in turn, will diminish some obstacles facing their teaching of students with LD.

The training module mainly contributed to improving the level of experimental group teachers because it included illustrative drawings, presentations, instructional videos, and the Zoom app to keep contact with the trainees, as well as presenting e-individual and group activities which help them get enthusiastic, and contribute to improving their awareness of cognitive and performance efficacy on the topics included in the module. The success of any training program is contingent on the extent to which trainees respond to the requirements of training and their familiarity with their training needs. The identification of training needs should be dynamic and flexible to keep up with the latest developments. This process is especially important because it is considered an indicator of the success of training programs. Additionally, a mutual and positive discussion between trainer and trainees in programs contained in this research contributed significantly to achieving success in improving teachers' awareness. This program is also characterized by integrity and comprehensiveness; that is, it included diverse cognitive and social aspects and micro-counseling responses that supported and enhanced teachers' awareness, knowledge, and communication skills on how they deal with twice-exceptional students. The program helped to crystalize cognitive and metacognitive skills and change some irrational beliefs embraced by teachers on diagnosing and identifying these students. In addition, the program also helped to improve electronic skills, particularly those related to e-learning; that is, teachers can practice teaching strategies with twice-exceptional students online or via Moodle.

In summary, in-service training programs should be pursued to develop human resources and providers in Special Education settings by enriching the knowledge and skills needed to heighten their competency and productivity. General educational institutions focus on programs for the preparation of teachers. In-service training programs for teachers of students with LD are necessary for bringing about the desired change and for providing modern teaching strategies, as well as being crucial in improving personal, cognitive, performance, and productive self-efficacy leading factors in shaping positive attitudes from within the teaching profession towards teachers of students with LD (Al-Zoubi, Rahman, \& Ismail, 2010; Suhail \& Rahman, 2011). On the other hand, the training programs module contributed to modifying attitudes of parents of students with LD towards the Jordanian Resource Room program (Al-Zoubi \& Rahman, 2014).

The aim of this research is not only to explore the effectiveness of the training module in elevating awareness of teachers of students with LD and GSLD but also to deliver a message about the importance of gifted education programs in the Sultanate of Oman. This will contribute to identifying GSLD who are part of these programs, whose effect was proved in previous studies, particularly their role in the education of the gifted, improvement of personal, emotional and psychological dimensions, and creating leadership able to keep up with present and future requirements (Al-Zoubi \& Bani, 2015). These programs also include enrichment activities that play an important role in improving cognitive, academic, and creative abilities in students (Al-Zoubi, 2014). Higher education institutions should fulfill their responsibilities in taking care of the gifted and developing them by including college programs, course enrichment programs, and activities with goals focusing on developing reasoning, cognitive, and metacognitive skills of the academically gifted students in these institutions (Al-Gaseem, Bakkar, \& Al-Zoubi, 2020).

\section{Conclusion}

The training module provided theoretical and practical information about GSLD and improved self-awareness of teachers of students with LD. This information may help to identify this category, which receives a great deal of interest in academic LD, but their distinguished abilities do not receive this kind of interest. Therefore, teachers of students with LD bear a heavy burden of identifying GSLD and teaching them with their peers with LD in Omani Resource Rooms. Teachers of this category need training programs helping them to identify GSLD. It is hopeful that teachers of students with LD and the Omani Ministry of Education will make use of the training module and the SAS and apply the general findings of this research to Omani educational governorates. 


\section{References}

Agarwal, A., \& Singh, Y. (2011). The gifted children with learning disability. Indian Streams Research Journal, 1(1), 1-4.

Al-Dababneh, K., Al-Masa'deh, M., \& Oliemat, E. (2014). The effect of a training programme in creativity on developing the creative abilities among children with visual impairment. Early Child Development and Care, 185(2), 317-339. Available at: https://doi.org/10.1080/03004430.2014.924113.

Al-Gaseem, M., Bakkar, B., \& Al-Zoubi, S. (2020). Metacognitive thinking skills among talented science education students. Journal for the Education of Gifted Young Scientists, 8(2), 897-904. Available at: https://doi.org/10.17478/jegys.707205.

Al-Hroub, A. (2014). Identification of dual-exceptional learners. Procedia-Social and Behavioral Sciences, 116, 63-73. Available at: https://doi.org/10.1016/j.sbspro.2014.01.169

Al-Hroub, A., \& Krayem, M. (2018). Teachers' knowledge and perceptions on ADHD and overexcitabilities in gifted learners. International Journal for Talent Development and Creativity, 6(2), 35-42.

Al-Hroub, A. (2010b). Perceptual skills and Arabic literacy patterns for mathematically gifted children with learning difficulties in Jordan. The British Journal of Special Education, 37(1), 25-38.

Al-Hroub, A. (2007). Parents' and teachers' contributions to identifying the unusual behavioural patterns of mathematically gifted children with learning difficulties (MG/LD) in Jordan. The Psychology of Education Review, 31(1), 8-16.

Al-Hroub, A. (2010a). Developing assessment profiles for mathematically gifted children with learning difficulties in England. Journal of Education for the Gifted, 34(1), 7-44.

Al-Mamari, K. (2017). Resource rooms as one of the alternatives in supporting children with learning difficulties in first cycle in the basic education in the Sultanate of Oman. Doctoral Disertation, UK, University of Southampton.

Al-Zoghby, A. (2014). The effectiveness of a training program based on the social cognitive theory in developing the professional self efficacy for special education students. Journal of Educational and Psychological Sciences, 15(2), 583-627.

Al-Zoubi. (2019). Obstacles of using the Edmodo platform in the Omani Resource Room program. International Interdisciplinary Journal of Education, 8(5), 130-135.

Al-Zoubi, S., \& Al-Zoubi, S. (2020). Prevalence of articulation errors among Jordanian gifted students with dyslexia. Journal for the Education of Gifted Toung Scientists, 8(1), 533-548.

Al-Zoubi, S., \& Rahman, B. A. M. (2014). The effect of a training program on modifying attitudes of parents of students with learning disabilities toward resource rooms in Jordan. International Interdisciplinary Journal of Education, 3(1), 41-57.

Al-Zoubi, S., \& Nefaie, R. (2019). Challenges facing learning disabilities program at Tabuk in the Kingdom of Saudi Arabia. Dirasat: Educational Sciences, 46(1), 619-633.

Al-Zoubi, S., \& Rahman, B. A. M. (2016). Mainstreaming in Kingdom of Saudi Arabia: obstacles facing learning disabilities resource room. Journal of Studies in Education, 6(1), 37-55.

Al-Zoubi, S., Rahman, B. A. M., \& Ismail, H. (2010). The effect of in-service training program in improving performance competencies for learning disabilities resource room teachers in Jordan. Educators Digest, 1O(1), 4-11.

Al-Zoubi, S. (2014). Effects of enrichment programs on the academic achievement of gifted and talented students. Journal for the Education of the Young Scientist and Giftedness, 2(2), 22-27.

Al-Zoubi......., S., \& Bani, A. R. M. (2015). Talented students' satisfaction with the performance of the gifted centers. Journal for the Education of Gifted Young Scientists, 4(1), 1-20.

Al-Hroub, A., \& Whitebread, D. (2008). Focus on practice: Teacher nomination of 'mathematically gifted children with specific learning difficulties' at three state schools in Jordan. British Journal of Special Education, 35(3), 152-164. Available at: https://doi.org/10.1111/j.1467-8578.2008.00379.x.

Al Hajeri, A. (2015). Developing a scale to identify gifted pupils with disabilities in the primary schools in Bahrain. Journal of Educational and Psychological Sciences, 16(1), 13-42. Available at: https://doi.org/10.12785/jeps/160101.

Assouline, S. G., Foley, N. M., \& Whiteman, C. (2010). Cognitive and psychosocial characteristics of gifted students with written language disability. Gifted Child Quarterly, 54(2), 102-1 15. Available at: https://doi.org/10.1177/0016986209355974.

Bakhiet, S., \& Essa, Y. (2012). Survey study to identify gifted children with learning disabilities at learning disability programs in Riyadh. Journal of Educational and Psychological Sciences, 13(4), 307-332.

Beckmann, E., \& Minnaert, A. (2018). Non-cognitive characteristics of gifted students with learning disabilities: An in-depth systematic review. Frontiers in Psychology, 9, 1-20. Available at: https://doi.org/10.3389/fpsyg.2018.00504.

Buică-Belciu, C., \& Popovici, D.-V. (2014). Being twice exceptional: Gifted students with learning disabilities. Procedia-Social and Behavioral Sciences, 127, 519-523. Available at: https://doi.org/10.1016/j.sbspro.2014.03.302.

Cline, S., \& Hegeman, K. (2001). Gifted children with disabilities. Gifted Child Today, 24(3), 16-24. Available at: https://doi.org/10.4219/gct2001-542.

Gargiulo, R. (2012). Special education in contemporary society: an introduction to exceptionality (4th ed.). Washington, DC: SAGE Publications.

Hallahan, D., Kauffman, J., \& Pullen, P. (2014). Exceptional learners: An introduction to special education (12th ed.). Upper Saddle River, NJ: Pearson Education Inc.

Josephson, J., Wolfgang, C., \& Mehrenberg, R. (2018). Strategies for supporting students who are twice-exceptional. The Journal of Special Education Apprenticeship, 7(2), 1-10.

Kurup, A., \& Dixit, S. (2016). Gifted with disabilities: The Twice exceptional in India. Indian Educational Revierw, 54(2), 7-25.

Lovett, B., \& Sparks, R. (2011). The identification and performance of gifted students with learning disability diagnoses: A quantitative synthesis. Journal of Learning Disabilities, 46(4), 304-316.

Lovett, B. J. (2013). The science and politics of gifted students with learning disabilities: A social inequality perspective. Roeper Review, 35(2), 136-143. Available at: https://doi.org/10.1080/02783193.2013.766965.

Maddocks, D. L. (2018). The identification of students who are gifted and have a learning disability: A comparison of different diagnostic criteria. Gifted Child Quarterly, 62(2), 175-192. Available at: https://doi.org/10.1177/0016986217752096.

Morrison, W. F., \& Rizza, M. G. (2007). Creating a toolkit for identifying twice-exceptional students. Journal for the Education of the Gifted, 31(1), 57-76. Available at: https://doi.org/10.4219/jeg-2007-513.

Pecháčková, Y., Drahokoupilová, M., \& Krámová, M. (2015). Professional self-efficacy of students in the field of teaching. Procedia-Social and Behavioral Sciences, 171, 680-685. Available at: https://doi.org/10.1016/j.sbspro.2015.01.177.

Pepanyan, M., Fisher, M., \& Wallican-Green, A. (2018). Faces on mars lesson: Incorporating art, thinking skills, and disability differentiation strategies for twice-exceptional gifted students. Journal of STEM Arts, Crafts, and Constructions, 3(1), 93-102.

Reis, S. M., Baum, S. M., \& Burke, E. (2014). An operational definition of twice-exceptional learners: Implications and applications. Gifted Child Quarterly, 58(3), 217-230. Available at: https://doi.org/10.1177/0016986214534976.

Silverman, L. (2005). Gifted children with learning disabilities. In N. Colangelo \& G. A. Davis (Eds.). Handbook of Gifted Education (3rd ed., pp. 533-546). Boston, MA: Allyn \& Bacon.

Suhail, A.-Z. M., \& Rahman, M. S. B. A. (2011). The effects of a training program in improving instructional competencies for special education teachers in Jordan. Educational Research, 2(3), 1021-1030.

Wang, Z., Cheng, L., \& Wang, H. (2017). A study on the training mode of electronic application- oriented undergraduate with industry needs. Journal Of Education And E-Learning Research, 4(2), 37-40. Available at: https://doi.org/10.20448/journal.509.2017.42.37.40.

Wormald, C. (2008). Teachers' knowledge of gifted learning disabled students in NSW. Dual Exceptionality, 27(3), 87-94.

Asian Online Journal Publishing Group is not responsible or answerable for any loss, damage or liability, etc. caused in relation to/arising out of the use of the content. Any queries should be directed to the corresponding author of the article. 